\title{
BMJ open Work disability benefits due to musculoskeletal disorders among Brazilian private sector workers
}

\author{
E R Vieira, ${ }^{1}$ P R Albuquerque-Oliveira, ${ }^{2}$ A Barbosa-Branco ${ }^{3,4}$
}

To cite: Vieira ER, Albuquerque-Oliveira PR, Barbosa-Branco A. Work disability benefits due to musculoskeletal disorders among Brazilian private sector workers. BMJ Open 2011;: $: \mathrm{e} 000003$.

doi:10.1136

bmjopen-2011-000003

- Prepublication history for this paper is available online. To view these files please visit the journal online (http:// bmjopen.bmj.com).

Received 23 September 2010 Accepted 23 January 2011

This final article is available for use under the terms of the Creative Commons Attribution Non-Commercial 2.0 Licence; see http://bmjopen.bmj.com

${ }^{1}$ Department of Physical Therapy, Florida International University, Miami, Florida, USA

${ }^{2}$ Ministry of Social Security and Faculty of Mechanical Engineering, University of Brasilia, Brasilia, Brazil

${ }^{3}$ Faculty of Health Sciences, University of Brasilia,

Brasilia, Brazil

${ }^{4}$ Institute for Work \& Health, Toronto, Canada

Correspondence to Dr Edgar Ramos Vieira; EVieira@fiu.edu

\author{
ABSTRACT \\ Objective: To evaluate the prevalence and \\ characteristics of disability benefits due to \\ musculoskeletal disorders (MSD) granted to Brazilian \\ private sector workers.
}

Methods: This was a population-based epidemiological study of MSD-related benefits among registered private sector workers $(n=32959329)$. The prevalence (benefits/10 000 workers/year) of work disability benefits was calculated by gender, age, state, Human Development Index (HDI), economic activity, MSD type and work-relatedness.

Results: The prevalence of MSD-related benefits in Brazil among registered private sector workers in 2008 was 93.6/10000 workers. The prevalence increased with age, and was higher for women (112.2) than for men (88.1), although the former had shorter benefit duration. The gender-adjusted prevalence by state varied from 16.6 to 90.3 for non-work-related, and from 7.8 to 59.6 for work-related benefits. The Brazilian states with a high-very high HDI had the highest prevalence. The top four most common types of MSD-related benefits were due to back pain, intervertebral disc disorders, sinovitis/tenosynovitis and shoulder disorders.

Conclusion: MSD is a frequent cause of work disability in Brazil. There were differences in prevalence among economic activities and between states grouped by HDI. This study demonstrates that further evaluation of the contributing factors associated with MSD-related disability benefits is required. Factors that should be considered include production processes, political organisation, socioeconomic and educational characteristics, the compensation and recording systems, and employee-employer power relationships. These factors may play an important role in the prevalence of MSD-related disability benefits, especially in countries with large socioeconomic iniquities such as Brazil.

\section{INTRODUCTION}

Musculoskeletal disorders (MSD) affect muscles, bones, nerves, tendons, ligaments, joints, cartilage and spinal discs. MSD result in malfunctioning of the musculoskeletal system with or without diagnosable injuries ${ }^{1}$

\section{ARTICLE SUMMARY}

Article focus

- Musculoskeletal disorders (MSD) are a major cause of disability worldwide.

- The prevalence and distribution of MSD among Brazilian workers are not well known.

- This article evaluates the prevalence and characteristics of disability benefits due to MSD granted to Brazilian private sector workers.

Key messages

- The prevalence of MSD-related benefits among registered Brazilian private sector workers in 2008 was $93.6 / 10000$ workers, with the top four most common benefits being due to back pain, intervertebral disc disorders, sinovitis/tenosynovitis and shoulder disorders.

- This study demonstrates that further evaluation of the contributing factors associated with MSDrelated disability benefits is required and should assess the production processes, political organisation, socioeconomic and educational characteristics, the compensation and recording systems, and employee-employer power relationships.

- These factors may play an important role in the prevalence of MSD-related disability benefits, especially in countries with large socioeconomic iniquities such as Brazil.

and are a major cause of disability and time off work. For example, >600 000 American workers (of a total workforce of approximately 140 million) spend time off work due to MSD each year. ${ }^{2}$ In 2004, MSD accounted for $>57$ million healthcare visits in the USA ( $60 \%$ of all injury-related visits). Back pain alone accounted for $>53$ million healthcare visits, 313.5 million bed-days and 186.7 million days off work. ${ }^{3}$ Similarly, MSD are one of the most common occupational health issues in Brazil. $^{4-6}$ In 2002, the Brazilian National Social Security Institute recorded 105514 cases of MSD among Brazilian workers insured for work-related disability $(n=22903311)$. However, the prevalence and distribution of MSD among 


\section{ARTICLE SUMMARY}

Strengths and limitations of this study

- All employed workers with a registered job in the private sector were analysed (32 959329 workers). Prevalence was adjusted by gender, age and category of benefit (work-related or nonwork-related). This initial descriptive study provides some baseline data on the magnitude of the problem. The data may be used for future comparisons and to evaluate the effectiveness of prevention programs. The strength of this paper is that it supplies information which could be useful in the implementation of an occupational health policy to reduce MSD. One of the limitations is that it only includes data from registered workers although there are many non-registered workers in Brazil. Another limitation is that this study depends on the quality of the data recorded by the National Insurer (NI) of the Brazilian Ministry of Social Insurance.

Brazilian workers are not as well described. Most Brazilian studies on MSD are limited to specific disorders/symptoms or occupations.

It has been estimated that in Sao Paulo city alone approximately 310000 workers had MSD in $2001 .^{7} \mathrm{~A}$ cross-sectional study found that $56 \%$ of the Brazilian bank workers evaluated had MSD symptoms affecting the upper limbs. ${ }^{8}$ Other cross-sectional studies found that $39 \%$ of Brazilian pottery workers and $71 \%$ of Brazilian hairdressers had MSD. ${ }^{9}{ }^{10}$ These data demonstrate that MSD are significant problem among Brazilian workers even though their prevalence among the larger working population is not clearly established.

Brazil accounts for approximately $65 \%$ of Central and South American trade. ${ }^{11}$ Knowledge of the current MSD prevalence and distribution in Brazil is important for establishing the magnitude of the problem, increasing awareness, and designing and evaluating prevention programs. Therefore, the objectives of this study were to evaluate and present data on the prevalence and characteristics of MSD-related benefits among private sector workers in Brazil. In addition, because the socioeconomic development of the different Brazilian states varies greatly, we also grouped and compared the prevalence of MSD-related benefits among states according to their Human Development Index (HDI). ${ }^{12} 13$ The HDI is a composite index that classifies countries, states and cities as developed (very high HDI $>0.85$, high HDI $0.70-0.85$ ), developing (medium HDI $0.55-0.70$ ) or underdeveloped (low HDI $0.40-0.55$, very low HDI $<0.40$ ). The HDI is based on data on life expectancy, education and per capita gross domestic product.

\section{METHODS}

Brazilian policies on work absences due to health issues

Registered private sector employees contribute at least $8 \%$, and employers at least $12 \%$, of workers' salaries to the National Insurer (NI) of the Ministry of Social Insurance. The NI contribution covers a wide range of benefits, including maternity leave, retirement age, time off work and non-work-related disability. In addition, all employees must be insured for work-related disability; this additional NI insurance premium is paid by employers.

All absences due to disabilities must be certified by a physician. For the first 15 days of leave, benefits are paid by the employer regardless of work relatedness. ${ }^{14}$ Thereafter, the NI pays the benefits. After 15 days of sickness absence, the worker submits a claim to the NI. The claim is reviewed by an auditor physician who determines if the worker has a work disability or not. The physician then classifies the MSD as work- or non-workrelated based on epidemiological evidence, information presented by the employer or employee, and patient/ MSD history. Workers cannot be dismissed while in receipt of disability benefit, but they may be dismissed upon return to work if they received non-work-related benefits. In case of work-related disability, the worker cannot be dismissed for at least 1 year after return to work. These socio-economic and legal factors play a major role in the worker's decision to claim or not claim benefits, and demonstrate the importance of determining whether or not workers' disability is work related.

\section{Study population}

The economically active Brazilian population in 2008 was estimated to be 99500202 . Approximately $40 \%$ of the economically active population was insured by the NI $(n=39652510)$. Self-employed workers $(\sim 20 \%$ of NI insured workers) were not included because reliable information on the denominator (exposed population) was not available. Thus, all employed workers with a registered job in the private sector were analysed, resulting in a study population comprising $\sim 80 \%$ of the NI insured workers $(n=32959329)$. The study protocol was approved by the institutional research ethics board.

\section{Case definition}

Cases were defined as new MSD-related benefits granted by the NI from 1 January to 31 December 2008. Each worker received only one benefit regardless of the number of jobs he/she had. Claims filed for the same diagnosis within 60 days of return to work were considered a continuation of the previous claim.

\section{Data sources}

The information used was obtained from two databases: (1) the Unique Benefit System of the National Social Security Institute, and (2) the National Cadastre of Social Information. The first database includes all benefits granted and paid by the NI and contains information on age, diagnosis (International Classification of Diseases, 10th revision (ICD-10) codes), gender, category of benefit (work-related or non-workrelated), economic activity, ${ }^{15}$ duration, benefit cost and geographical location of employment. This database 
was used to identify the cases (ie, the numerator) for prevalence calculations.

The second database, the National Cadastre of Social Information, contains information on workers in all registered companies. All new jobs generated during the preceding month are recorded. The monthly reports include the total number of employees, payroll and other information, as well as new hires and layoffs. ${ }^{16}$ This database provided the total number of workers (ie, denominator) for our study.

We calculated the annual number of workers using the 2008 monthly average. Economic activities were classified according to the SIC-2007. The Brazilian SIC-2007 follows the UK, European NACE and United Nation's ISIC, all of which are consistent in terminology. ${ }^{15}$ The SIC-2007 is divided into 21 (A to U) sections (eg, manufacturing), 88 divisions (eg, beverages manufacturing), and $\sim 700$ classes with four- to five-digit codes. Finally, the HDI score of the different states was obtained from the Brazilian chapter of the United Nations Development Program. ${ }^{13}$

\section{Data analysis}

The prevalence of MSD-related benefits was calculated and stratified by MSD type (ICD-10), economic activity (SIC-2007), category of benefit (work- or non-workrelated), gender (male or female), age group $(<20$, $20-29,30-39,40-49,50-59$ or $\geq 60$ years of age) and state of employment. The numerator was all MSD-related benefits paid by the NI during the study period. The denominator was the total number of registered private sector workers.

The prevalences of MSD-related benefits, standardised by gender and age, were calculated for comparison with economic activities using the total population as reference. The prevalences of MSD-related benefits that were work- and non-work-related were calculated. The prevalence figures were presented as benefits/10000 workers/year. Prevalence ratios (PR) were calculated by dividing the prevalence among females by the prevalence among males, and the prevalence of nonwork-related benefits by the prevalence of work-related benefits. In addition, we compared the prevalence of MSD-related benefits among the states according to their HDI. ${ }^{12}{ }^{13}$ We grouped states as having high-very high HDI $(>0.80)$, medium-high HDI $(>0.70,<0.80)$ or medium-low HDI $(<0.70)$.

\section{RESULTS}

In 2008, the Brazilian Social Security Institute granted 1384242 disability benefits to registered private sector workers. Among these, 304933 were MSD-related (ICD10 , category XIII), resulting in a prevalence of 93.6 MSDrelated benefits/10 000 workers/year.

Table 1 presents the distribution and characteristics of MSD-related benefits by age group, gender, benefit category (non-work-related or work-related) and MSD type (ICD-10 classification). Most benefits were paid to 30-49-year-old workers (59\%). The duration of the benefits increased with age. The prevalence of MSDrelated benefits was higher for women (112.2) than for men (88.1), but the former had a shorter duration of benefit, regardless of the benefit category and MSD type. The PR for non-work-related to work-related MSD benefits was 2.1. Most benefits paid were due to back problems $(45 \%)$.

Table 2 shows that there was a large variation in the prevalence of MSD-related benefits between Brazilian states and between age groups. There were differences between prevalence when the states were grouped by HDI. ${ }^{12}$ States with high-very high HDI had the highest prevalence of MSD-related benefits. Gender-adjusted prevalence by state varied from 16.6 to 90.3 for nonwork-related benefits, and from 7.8 to 59.6 for workrelated benefits. The differences between the highest and lowest prevalence of MSD-related benefits by age group were: $<20$ years, 20 times; $20-29$ years, 8 times; 30-39 years, 6 times; $40-49$ years, 4 times; $50-59$ years, 5 times; and $60+$ years, 4 times.

Table 3 shows the prevalence and prevalence ratios for the 22 economic activities with the highest prevalence of MSD-related benefits. The prevalence was higher among females than among males. The overall PR was 1.3, meaning that women received $30 \%$ more MSD-related benefits than men. There were also differences in gender-adjusted, and gender-, age- and category of benefit-adjusted prevalence among the economic activities, with sewage workers having the highest prevalence of benefits, followed by programming/ broadcasting activities and wood/products manufacturing (except furniture).

Table 4 shows the prevalence of MSD-related benefits for the most frequent types of MSD by gender and benefit category. The four most common types of MSDrelated benefits were due to back pain, intervertebral disc disorders, sinovitis/tenosynovitis and shoulder disorders. In general, women had more benefits, and non-work related benefits were more frequent.

\section{DISCUSSION}

The prevalence of MSD-related benefits/10000 registered Brazilian private sector workers in 2008 was 94 . The prevalence increased with age, and was higher for women (112) than for men (88), although the former had shorter benefit duration. The genderadjusted prevalence by state varied from 17 to 90 for non-work-related, and from 8 to 60 for work-related benefits. The most common types of MSD-related benefits were due to back pain, intervertebral disc disorders, sinovitis/tenosynovitis and shoulder disorders.

The demands of the work tasks within the industries are likely related to MSD among registered Brazilian private sector workers. MSD may occur when the musculoskeletal system is used beyond its physiological limits due to cumulative or single event exposures to one or multiple long lasting and/or excessive exertions. ${ }^{17}$ 
Table 1 Frequency, median age, duration, cost of benefits and income replacement for Brazilian private sector workers receiving MSD-related benefits in 2008

\begin{tabular}{|c|c|c|c|c|c|}
\hline Characteristic & $\begin{array}{l}\text { No. of } \\
\text { claims }\end{array}$ & $\begin{array}{l}\text { Median } \\
\text { age }\end{array}$ & $\begin{array}{l}\text { Median } \\
\text { no. of days } \\
\text { off work }\end{array}$ & $\begin{array}{l}\text { Median } \\
\text { benefit cost } \\
(\mathrm{R} \$)\end{array}$ & $\begin{array}{l}\text { Median income } \\
\text { replacement } \\
\text { (R\$) }\end{array}$ \\
\hline \multicolumn{6}{|l|}{ Age group (years) } \\
\hline$<20$ & 1653 & 19 & 46 & 743.24 & 463.14 \\
\hline $20-29$ & 56951 & 26 & 53 & 1082.82 & 579.47 \\
\hline $30-39$ & 87890 & 35 & 62 & 1531.54 & 722.48 \\
\hline $40-49$ & 93296 & 44 & 67 & 1881.93 & 827.63 \\
\hline $50-59$ & 56423 & 53 & 71 & 1852.75 & 768.87 \\
\hline$\geq 60$ & 8720 & 62 & 76 & 1778.00 & 695.52 \\
\hline \multicolumn{6}{|l|}{ Gender } \\
\hline Male & 170849 & 40 & 66 & 1909.56 & 852.94 \\
\hline Female & 134084 & 40 & 61 & 1246.36 & 579.13 \\
\hline \multicolumn{6}{|l|}{ Benefit category } \\
\hline Non-work-related & 205772 & 41 & 64 & 1601.25 & 722.49 \\
\hline Work-related & 99161 & 39 & 62 & 1480.17 & 684.15 \\
\hline \multicolumn{6}{|l|}{ MSD type (ICD-10) } \\
\hline Arthropathies & 64059 & 40 & 68 & 1718.31 & 728.57 \\
\hline $\begin{array}{l}\text { Systemic connective tissue } \\
\text { disorders }\end{array}$ & 1576 & 35 & 81 & 1784.19 & 612.10 \\
\hline Dorsopathies & 137350 & 42 & 64 & 1587.58 & 725.01 \\
\hline Soft tissue disorders & 95973 & 38 & 60 & 1199.83 & 678.16 \\
\hline $\begin{array}{l}\text { Osteopathies/ } \\
\text { chondropathies }\end{array}$ & 3541 & 34 & 79 & 2061.17 & 718.42 \\
\hline $\begin{array}{l}\text { Other MSD and connective } \\
\text { tissue disorders }\end{array}$ & 2434 & 34 & 64 & 1588.11 & 690.05 \\
\hline
\end{tabular}

However, MSD are multifactorial in nature; genetics, morphology and psychosocial characteristics, in addition to biomechanical factors act together to precipitate these disorders. ${ }^{17}$

Women received more MSD-related benefits than men, but these benefits were of shorter duration. Men had a higher prevalence of MSD-related benefits than women in only six of the top 22 economic activities. These six activities employ predominantly male workers. Other studies also found higher prevalence of MSD among women. ${ }^{18}$ The higher prevalence of MSD among women may be related to differences in work characteristics, and home and parenthood activities. ${ }^{19}$

Systemic connective tissue disorders (eg, those affecting the skin and blood vessels) had longer duration, independent of gender and benefit category. Soft tissue disorders (eg, those affecting muscles and tendons) had the shortest duration. This difference in duration is due to the fact that systemic connective tissues disorders take longer to heal than more localised muscle and/or tendon injuries. ${ }^{20} 21$

Sewage workers had 7.9 times, and programming and broadcasting workers had 2.4 times more MSD-related benefits than the general population of registered Brazilian private sector workers. For work-related benefits, sewage workers had 9.5 times, and workers involved in the manufacture of wood and wood products had 3.1 times higher prevalence than the total population. Job characteristics and occupational ergo- nomic stressors are important aetiological factors for MSD of the lower back and upper extremities. ${ }^{22}$ Working in small, confined spaces and the heavy workload of sewage industry employees may contribute to the higher prevalence of MSD-related benefits among these workers than among most other economic activities. In addition, being municipal employees and having low socioeconomic status could also have contributed to the high prevalence of MSD found among sewage workers. ${ }^{23} 24$ Despite the fact that sewage workers are employed under the same regulations as the private sector, as employees of mixed public/private companies they enjoy higher job security than private sector employees. Lund found that municipal workers from Sweden and Denmark contributed disproportionally to disability absence longer than 7 days. $^{25}$

The factors affecting disability benefits for programming and broadcasting workers may be different. No studies on the risks affecting this economic activity were found; however, these workers are exposed to several established biomechanical and psychosocial risks including highly repetitive precision tasks, awkward postures, computer work, temporal pressure and stress, maximisation of minor mistakes, shift work and fatigue. ${ }^{1} 1726$ In one study, it was found that Brazilian systems analysts' mental and physical health were affected by working conditions including workload, equipment, work environment and workstation design, gender and level of worker participation. ${ }^{27}$ Other factors 
Table 2 Prevalence of MSD-related benefits/10000 registered Brazilian private sector workers in 2008, by state and HDI per age group: crude and adjusted prevalence by gender, age and category of benefit $(\mathrm{g} / \mathrm{a} / \mathrm{cb})$

\begin{tabular}{|c|c|c|c|c|c|c|c|c|}
\hline \multirow{2}{*}{$\begin{array}{l}\text { HDI classification: index } \\
\text { State: index }\end{array}$} & \multicolumn{7}{|c|}{ Age group (years) } & \multirow{2}{*}{$\begin{array}{l}\text { g/a/cb } \\
\text { Adj }\end{array}$} \\
\hline & $<20$ & $20-29$ & $30-39$ & $40-49$ & $50-59$ & $\geq 60$ & Crude & \\
\hline Medium-low: 0.68 & 4.8 & 30.2 & 62.4 & 109.3 & 177.8 & 120.8 & 67.9 & 66.3 \\
\hline Alagoas: 0.68 & 3.3 & 43.9 & 77.8 & 134.5 & 219.2 & 148.1 & 88.0 & 84.9 \\
\hline Maranhão: 0.68 & 5.8 & 20.9 & 51.1 & 89.6 & 144.0 & 101.8 & 53.3 & 53.5 \\
\hline Medium-high: 0.75 & 6.2 & 35.5 & 62.8 & 102.5 & 156.0 & 132.7 & 65.1 & 65.1 \\
\hline Acre: 0.75 & 0.0 & 10.9 & 33.6 & 68.3 & 83.1 & 99.2 & 32.5 & 34.7 \\
\hline Mato Grosso: 0.79 & 10.3 & 40.7 & 75.7 & 136.2 & 236.5 & 285.7 & 80.0 & 88.7 \\
\hline Amapá: 0.78 & 10.1 & 17.5 & 24.0 & 47.7 & 85.0 & 59.4 & 26.5 & 30.3 \\
\hline Amazonas: 0.78 & 1.9 & 74.4 & 130.8 & 148.7 & 165.3 & 137.9 & 105.4 & 108.0 \\
\hline Bahia: 0.74 & 5.4 & 36.9 & 67.7 & 127.3 & 196.2 & 148.5 & 76.2 & 75.1 \\
\hline Ceará: 0.72 & 4.7 & 29.7 & 42.3 & 68.2 & 113.7 & 84.5 & 45.7 & 46.1 \\
\hline Rondônia: 0.78 & 8.3 & 32.6 & 76.7 & 127.3 & 180.1 & 182.3 & 68.4 & 76.5 \\
\hline Roraima: 0.75 & 0.0 & 32.8 & 47.0 & 78.6 & 195.1 & 170.0 & 50.1 & 57.6 \\
\hline Rio Grande do Norte: 0.74 & 18.9 & 50.8 & 64.1 & 95.8 & 144.4 & 155.2 & 69.1 & 69.2 \\
\hline Sergipe: 0.74 & 2.5 & 28.0 & 54.8 & 83.9 & 119.7 & 89.4 & 53.1 & 52.8 \\
\hline Tocantins: 0.76 & 1.7 & 17.3 & 37.7 & 71.7 & 120.8 & 121.1 & 41.5 & 42.1 \\
\hline Pará: 0.76 & 1.3 & 36.7 & 84.4 & 147.3 & 241.7 & 201.1 & 87.4 & 88.1 \\
\hline Paraíba: 0.72 & 4.3 & 29.6 & 40.9 & 59.6 & 91.0 & 70.5 & 45.4 & 42.5 \\
\hline Pernambuco: 0.72 & 7.5 & 29.7 & 54.1 & 82.8 & 107.9 & 73.3 & 53.9 & 52.3 \\
\hline Piauí: 0.71 & 2.4 & 17.0 & 27.6 & 59.0 & 106.9 & 161.0 & 38.4 & 37.4 \\
\hline High-very high: 0.82 & 12.1 & 53.5 & 99.0 & 156.7 & 210.9 & 154.9 & 97.2 & 97.5 \\
\hline Mato Grosso do Sul: 0.80 & 10.1 & 63.0 & 105.9 & 167.3 & 253.4 & 212.8 & 107.3 & 111.3 \\
\hline Paraná: 0.82 & 16.5 & 72.1 & 115.6 & 176.0 & 261.3 & 204.8 & 112.2 & 117.1 \\
\hline Espírito Santo: 0.80 & 12.4 & 42.3 & 89.5 & 162.6 & 260.6 & 228.3 & 97.0 & 97.4 \\
\hline Goiás: 0.80 & 8.3 & 35.7 & 67.3 & 104.2 & 155.8 & 152.7 & 64.1 & 67.9 \\
\hline Rio Grande do Sul: 0.83 & 16.1 & 66.4 & 112.7 & 173.2 & 227.5 & 168.3 & 110.0 & 109.7 \\
\hline Rio de Janeiro: 0.83 & 11.8 & 68.4 & 121.6 & 172.5 & 186.0 & 99.7 & 115.9 & 109.1 \\
\hline Minas Gerais: 0.80 & 8.3 & 40.5 & 75.0 & 119.7 & 175.6 & 139.5 & 76.1 & 75.8 \\
\hline Distrito Federal: 0.87 & 11.1 & 37.3 & 61.0 & 91.6 & 133.0 & 132.8 & 61.5 & 61.1 \\
\hline Santa Catarina: 0.84 & 25.8 & 84.8 & 151.2 & 253.2 & 373.8 & 318.0 & 147.0 & 156.3 \\
\hline São Paulo: 0.83 & 9.8 & 46.9 & 93.3 & 150.0 & 200.2 & 147.0 & 90.8 & 91.4 \\
\hline Brazil: 0.75 & 11.6 & 51.5 & 94.1 & 150.1 & 206.4 & 154.5 & 93.6 & 93.6 \\
\hline
\end{tabular}

Adj, adjusted; HDI, Human Development Index; MSD, musculoskeletal disorders.

likely associated with the high prevalence of MSD-related benefits among programming and broadcasting workers are their higher level of education in comparison to most other occupational groups evaluated, their easier access to healthcare due to their higher wages, and possibly their increased ability to claim disability because of their educational level and worker-employer relationships.

In most Brazilian states, the prevalence of MSD-related benefits increased with age up to the 50-59 age group and then decreased for the $60+$ age group. The lower prevalence for the 60+ age group versus the 50-59 age group may be related to the fact that female workers are eligible to retire at 60 and male workers at 65 . However, reaching the eligible retirement age does not mean that workers actually retire. The decreased income upon retirement and the increased life expectancy lead workers to remain in the workforce after reaching retirement age. Also, some workers return to the work force soon after retiring. For example, for the 50-59 age group, men represent $67.2 \%$ of the working population, while for the $60+$ age group, men represent $76.3 \%$ of the workforce. This is further illustrated by the fact that in six states the prevalence of MSD-related benefits continued to increase in the 60+ age group.

Differences between the state prevalence of MSDrelated benefits were observed for all age groups, with young workers $(<20$ years old) having the highest variation. This may be explained by the healthy worker effect, where exposed individuals who developed MSD may have left employment earlier in their careers. Thus, only workers who are genetically and/or physically less prone to develop MSD remain in their jobs. ${ }^{28}$ However, over time, more and more workers develop MSD due to the cumulative effects of prolonged exposure to the risk factors for MSD. ${ }^{17}$ Also, the differences between states may be related to differences in economic activity and job categories. In addition, the duration of the benefits increased with age, as was reported in previous studies and reviews, and may be related to slower healing and changes in the characteristics of collagen and elastin with age. ${ }^{29} 30$

Some states had up to $60 \%$ higher gender-adjusted, and up to $70 \%$ higher age-adjusted MSD-related benefits 


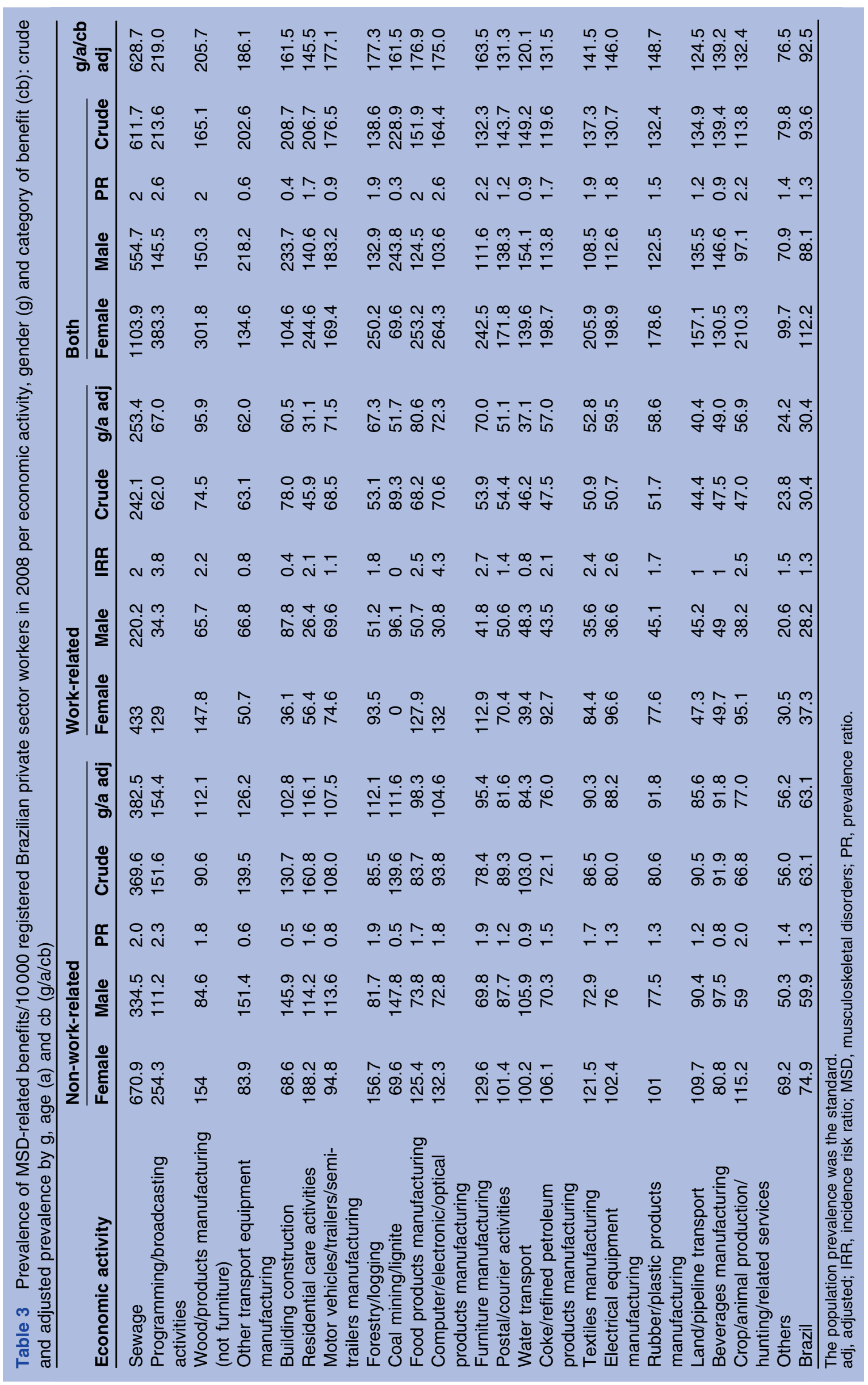


Table 4 Prevalence of MSD-related benefits/10000 registered Brazilian private sector workers in 2008, by type of MSD (ICD-10), gender and category of benefit

\begin{tabular}{|c|c|c|c|c|c|c|c|c|c|c|c|c|}
\hline \multirow[b]{2}{*}{ MSD type } & \multicolumn{4}{|c|}{ Non-work-related } & \multicolumn{4}{|c|}{ Work-related } & \multicolumn{4}{|l|}{ Both } \\
\hline & $\mathbf{F}$ & $\mathbf{M}$ & PR & Total & $\mathbf{F}$ & $\mathbf{M}$ & PR & Total & $\mathbf{F}$ & M & PR & Total \\
\hline Back pain (dorsalgia) & 20.0 & 15.9 & 1.3 & 16.8 & 9.5 & 12.9 & 0.7 & 11.1 & 29.5 & 28.8 & 1.0 & 27.9 \\
\hline Intervertebral disc disorders & 8.5 & 10.7 & 0.8 & 9.5 & 0.9 & 2.0 & 0.4 & 1.6 & 9.4 & 12.8 & 0.7 & 11.1 \\
\hline Sinovitis/tenosynovitis & 9.0 & 2.9 & 3.1 & 5.0 & 11.0 & 3.1 & 3.5 & 5.9 & 20.0 & 6.0 & 3.3 & 10.9 \\
\hline Shoulder disorders & 6.9 & 3.7 & 1.9 & 4.7 & 8.5 & 4.4 & 1.9 & 5.7 & 15.4 & 8.1 & 1.9 & 10.5 \\
\hline Knee disorders & 3.2 & 8.6 & 0.4 & 6.3 & 0.5 & 1.2 & 0.4 & 0.9 & 3.7 & 9.8 & 0.4 & 7.2 \\
\hline Other joint disorders & 3.7 & 2.5 & 1.5 & 2.8 & 1.4 & 0.9 & 1.6 & 1.1 & 5.2 & 3.4 & 1.5 & 3.9 \\
\hline Other enthesopathies & 2.2 & 0.9 & 2.4 & 1.4 & 2.2 & 1.1 & 2.0 & 1.5 & 4.5 & 2.1 & 2.1 & 2.9 \\
\hline Knee arthrosis & 2.3 & 1.9 & 1.2 & 2.0 & 0.2 & 0.2 & 0.9 & 0.2 & 2.5 & 2.1 & 1.2 & 2.2 \\
\hline Other soft tissue disorders & 3.1 & 0.9 & 3.5 & 1.7 & 0.5 & 0.2 & 2.6 & 0.3 & 3.7 & 1.1 & 3.3 & 2.0 \\
\hline Other arthrosis & 1.2 & 1.1 & 1.1 & 1.1 & 0.2 & 0.2 & 0.8 & 0.2 & 1.4 & 1.3 & 1.1 & 1.3 \\
\hline Cervical disc disorders & 1.3 & 0.8 & 1.7 & 0.9 & 0.2 & 0.1 & 1.4 & 0.2 & 1.5 & 0.9 & 1.7 & 1.1 \\
\hline Hip arthrosis & 0.7 & 1.0 & 0.7 & 0.9 & 0.0 & 0.1 & 0.5 & 0.0 & 0.7 & 1.1 & 0.7 & 0.9 \\
\hline Other bursopathies & 0.9 & 0.5 & 1.9 & 0.6 & 0.2 & 0.1 & 2.4 & 0.1 & 1.1 & 0.5 & 2.0 & 0.7 \\
\hline Other back problems & 0.6 & 0.3 & 2.3 & 0.4 & 0.5 & 0.2 & 2.9 & 0.3 & 1.1 & 0.4 & 2.5 & 0.6 \\
\hline Patellar disorders & 0.8 & 0.4 & 2.0 & 0.6 & 0.1 & 0.1 & 1.2 & 0.1 & 0.9 & 0.5 & 1.9 & 0.6 \\
\hline Soft tissue disorders & 0.5 & 0.2 & 2.5 & 0.3 & 0.5 & 0.2 & 2.6 & 0.3 & 1.0 & 0.4 & 2.6 & 0.6 \\
\hline Spondylosis & 0.6 & 0.5 & 1.1 & 0.5 & 0.1 & 0.1 & 0.8 & 0.1 & 0.6 & 0.6 & 1.1 & 0.6 \\
\hline Others & 9.2 & 7.1 & 1.3 & 7.6 & 0.8 & 1.1 & 0.8 & 0.9 & 10.1 & 8.2 & 1.2 & 8.6 \\
\hline All MSD & 74.9 & 59.9 & 1.3 & 63.1 & 37.3 & 28.2 & 1.3 & 30.4 & 112.2 & 88.1 & 1.3 & 93.6 \\
\hline
\end{tabular}

than the general population of Brazilian workers. The highest prevalence was found among the states with high-very high HDI, and the lowest prevalence was found among the states with medium-high HDI. This is an interesting finding indicating higher prevalence among the most productive and populous areas and is supported by the facts that productivity and gross domestic product (which is part of the HDI calculation) are closely related, and that $78 \%$ of registered Brazilian private sector workers live in states with high-very high HDI. This finding may be related to the more repetitive nature of tasks in more industrialised environments, but is likely also related to under-reporting in less developed environments with fewer jobs available. The reasons for and implications of these findings need to be further explored and are likely related to socio-politicoeconomical issues found in Brazil and other developing countries. ${ }^{31}$

Back pain, intervertebral disc disorders, sinovitis/ tenosynovitis and shoulder disorders were responsible for approximately $64 \%$ of all MSD-related benefits, $57 \%$ of all non-work-related benefits and $80 \%$ of all workrelated benefits. Back pain-related benefits were the most common for both genders and categories of benefit. Men had a higher prevalence of work-related back pain benefits, while women had a higher prevalence of non-work-related back pain benefits, and more work- and non-work-related sinovitis/tenosynovitis benefits.

Risk factors for back pain include heavy physical work, awkward postures, lifting, negative affectivity, low level of job control, high psychological demands and work dissatisfaction, younger age, female gender, race, smoking, increased weight and co-morbidities. ${ }^{1}$ Risk factors for wrist/hand MSD (including sinovitis/tenosynovitis) include heavy physical work, awkward postures, repetitive work, prolonged computer work, distress, older age, female gender, smoking, increased weight and co-morbidities. ${ }^{1}$ Complex interactions between work and home activities result in different exposures between men and women. These differences may help explain our findings.

The analyses of the states grouped by HDI may indicate under-reporting and consequently lack of access to social security benefits by workers in states with lower HDI. However, other factors should be considered, such as the migration of industrial enterprises from traditional industrial areas to less developed states because of tax benefits and lower labour costs. Another point to consider is that some states have a larger geographical area and greater socioeconomic variability. In addition, some states have higher industrial concentration in and around their capital cities, and more family based small agricultural enterprises in the countryside, possibly resulting in an unrepresentative mean HDI for these states. City level HDI comparisons may help to clarify these issues in future studies. Another issue to be considered is that the quality of the data including issues related to reporting and recording in different states and the databases in general may have affected the presented results. These issues are common to all studies with secondary analysis of previously recorded data. However, the direction of these potential influences cannot be ascertained.

Despite significant economic advances during the last decade, Brazil still lacks efficient occupational health 
and safety surveillance systems and effective prevention programs. ${ }^{30}$ This initial descriptive study will help to establish baseline data on the magnitude of the problem. The data may be used for future comparisons and to evaluate the effectiveness of prevention programs. Our findings may not be detailed enough to promote specific prevention programs, but they clearly demonstrate the need for such initiatives. Understanding the scale and distribution of MSD among Brazilian workers is a first step towards more effective data recording and better design of prevention programs.

MSD is a frequent cause of work disability in Brazil. There were differences in the prevalence between economic activities and between the states grouped by HDI. This study demonstrates that further evaluation of the factors associated with MSD-related disability benefits is required. Factors that should be considered include the production processes, political organisation, socioeconomic and educational characteristics, the compensation and recording systems, and employee-employer power relationships. These factors may play an important role in the prevalence of MSD-related disability benefits, especially in countries with large socioeconomic iniquities such as Brazil.

Acknowledgements The authors would like to thank Daniel Holt for helping to format and edit the paper, and Dr Denis Brunt for reviewing the manuscript before submission.

Funding This study was funded by the University of Brasilia and the Coordenacao de Aperfeicoamento de Pessoal de Nivel Superior (proc. no. 4239-09-1), Brazil.

Competing interests None.

Ethics approval The study protocol was approved by the University of Brasilia research ethics board.

Contributors ERV, PRAO and ABB were responsible for the study conception and design and drafting of the manuscript. PRAO and ABB performed the data collection. ERV, PRAO and $A B B$ performed the data analysis. $A B B$ obtained funding. ERV, PRAO and $A B B$ made critical revisions to the paper and approved the final manuscript.

Provenance and peer review Not commissioned; externally peer reviewed.

Data sharing statement Dataset kept by Dr Barbosa-Branco at anadergh@ hotmail.com. Consent was not obtained but the data are anonymised; the researchers had no access to the names of the subjects and risk of identification is low.

\section{REFERENCES}

1. da Costa BR, Vieira ER. Risk factors for work-related musculoskeletal disorders: a systematic review of recent longitudinal studies. Am J Ind Med 2010:53:285-323.

2. United Electrical Radio and Machine Workers of America. Health and Safety: Two Cheers for Half an Ergo Standard 1999. http://www. ranknfile-ue.org/h\&s1299.html (accessed 15 Sep 2010).

3. Agency for Healthcare Research and Quality. Healthcare Cost and Utilization Project, Nationwide Inpatient Sample. National Center for Health Statistics, National Hospital Ambulatory Medical Care Survey, and National Ambulatory Medical Care Survey, 2004. http://www. ahrq.gov/data/hcup (accessed 15 Sep 2010).

4. Brazilian Ministry of Social Welfare. Database of the Statistical Yearbook of Social Security 2003. http://www.seade.gov.br/produtos/ anuario/2003/tudo 2003.zip (accessed 15 Sep 2010).

5. Brazilian Centre for Studies and Analysis in Occupational Health. Situation of Workers' Health in Brazil and in Bahia- the Epidemiologic
Profile. CESAT / SUS Bahia, 2009. http://www.saude.ba.gov.br/ cesat/Informacoes/SituacaoST_2007.pdf (accessed 15 Sep 2010)

6. Jucá R, Costa H, Berzoini R. Basic Text of the National Policy on Occupational Health and safety. Official Press, 2005:85.

7. National Institute of Musculoskeletal Disorders Prevention. MSD Affects 310,000 Workers in São Paulo. Folha de Sao Paulo, 2001;9:9.

8. Lacerda EM, Nácul LC, Augusto LGS, et al. Prevalence and associations of symptoms of upper extremities, repetitive strain injuries (RSI) and 'RSI-like condition'. A cross sectional study of bank workers in Northeast Brazil. BMC Public Health 2005;5:107.

9. Melzer AC, Iguti AM. Working conditions and musculoskeletal pain among Brazilian pottery workers. Cad Saúde Pública 2010;26:492-502

10. Mussi G, Gouveia N. Prevalence of work-related musculoskeletal disorders in Brazilian hairdressers. Occup Med (Lond) 2008;58:367-9.

11. Veja. Weekly Magazine. Brazil has done More with Less. Data Sources: National Confederation for Industries. Veja, 2002:96-7.

12. United Nations Development Programme. The Human Development Index (HDI). http://hdrstats.undp.org/en/indicators/49806.html (accessed 15 Sep 2010).

13. United Nations Development Program. Brazil: 2008. http://www.pnud org.br/pobreza_desigualdade/reportagens/index.php? id01=3039\&lay=pde (accessed 15 Sep 2010).

14. Brazilian Ministry of Social Welfare. Occupational Health and Safety 2009. http://www.previdenciasocial.gov.br/imprimir.php?id=39 (accessed 15 Sep 2010).

15. SIC 2007. Standard Industrial Classification of Economic Activities, Version 2007. http://www.statistics.gov.uk/statbase/product.asp? vink=14012 (accessed 15 Sep 2010).

16. Brazilian Ministry of Social Welfare. Social Security Statistical Bulletin. 2009:15. http://www.mps.gov.br/arquivos/office/3_100225162737-618.xls (accessed 15 Sep 2010).

17. Kumar S. Theories of musculoskeletal injury causation. Ergonomics 2001;44:17-47.

18. Wijnhoven HA, de Vet HC, Picavet HS, et al. Prevalence of musculoskeletal disorders is systematically higher in women than in men. Clin J Pain 2006;22:717-24.

19. Strazdins L, Bammer G. Women, work and musculoskeletal health. Soc Sci Med 2004;58:997-1005

20. Harper FE, Maricq HR, Turner RE, et al. A prospective study of raynaud phenomenon and early connective tissue disease: a fiveyear report. Am J Med 1982;72:883-8.

21. Hogg-Johnson S, Cole DC. Early prognostic factors for duration on temporary total benefits in the first year among workers with compensated occupational soft tissue injuries. Occup Environ Med 2003;60:244-53.

22. National Research Council, Institute of Medicine. Musculoskeletal Disorders and the Workplace: Low Back Pain and Upper Extremities. Washington, DC: National Academy Press, 2001.

23. Gjesdal S, Bratberg E, Maeland JG. Musculoskeletal impairments in the Norwegian working population: the prognostic role of diagnoses and socioeconomic status. Spine (Phil Pa 1976) 2009;34:1519-25.

24. Piha K, Laaksonen M, Martikainen $\mathrm{P}$, et al. Interrelationships between education, occupational class, income and sickness absence. Eur $J$ Public Health 2010;20:276-80.

25. Lund T, Christensen KB, Vaez M, et al. Differences in sickness absence in Sweden and Denmark: the cross national HAKNAK study. Eur J Public Health 2008;19:343-9.

26. Côté P, van der Velde G, Cassidy JD, et al. The burden and determinants of neck pain in workers: results of the bone and joint decade 2000-2010: task force on neck pain and its associated disorders. Spine (Phil Pa 1976) 2008;33(4 Suppl):S60-74.

27. Rocha LE, Debert-Ribeiro M. Working conditions, visual fatigue, and mental health among systems analysts in São Paulo, Brazil. Occup Environ Med 2004;61:24-32.

28. Punnett L, Wegman DH. Work-related musculoskeletal disorders: the epidemiologic evidence and the debate. J Electromyogr Kinesiol 2004;14:13-23.

29. Cheadle A, Franklin G, Wolfhagen $C$, et al. Factors influencing the duration of work-related disability: a population-based study of Washington State workers' compensation. Am J Public Health 1994:84:190-6.

30. Turner JA, Franklin G, Turk DC. Predictors of chronic disability in injured workers: a systematic literature synthesis. Am J Ind Med 2000;38:707-22.

31. Economic Commission for Latin America and the Caribbean, United Nations Program for Development, International Labour Organization. Employment, human development and decent work: the recent Brazilian experience. Brasilia: 2008. 